\title{
Culture clash tarnishes the image of star laboratory
}

[MUNICH] A bitter feud between scientists and administrators is threatening to destroy the promising scientific reputation of a recently created research institute in the former East Germany that has been held up as a star of the country's restructured scientific landscape.

Problems at the Institute for Molecular Biology (IMB) in Jena, in the state of Thüringen, came to a head earlier this month with the resignation of the only scientist on its decision-making supervisory board, Manfred Eigen, the Nobel prizewinner and emeritus director of the Max Planck Institute for Biophysical Chemistry in Göttingen.

Following last year's resignation of Lothar Späth, head of the Jena-based optical company Carl-Zeiss, the supervisory board, or 'Kuratorium', now comprises only officials from the federal and state governments, which provide the IMB's DM25-million (US\$14.8-million) annual budget.

In his letter of resignation, Eigen argues that the scientific activities of the institute, which he helped to set up in 1991, have been compromised by weak scientific leadership and an inappropriate management structure which gives too much power to the administrative director.

Earlier this year, Eigen demanded a change in the institute's structure to correct these problems, as well as the resignations of the scientific director, Stefan Diekmann, द. and the administrative director. But he received no response, and he complains in his letter that he has received no official support for his efforts to protect the IMB from "scientific insignificance".

Eigen is the latest in a list of scientists who have Eigen: resigned in abandoned their associ- protest at regime. ation with the institute's

management. Others include Peter Schuster, head of the IMB's evolutionary biology research group and former scientific director, and Rudolf Rigler, professor of medical physics at the Karolinska Institute in Stockholm, Sweden, who was head of IMB's scientific council, the Wissenschaftlicher Beirat.

The IMB was founded after Germany's science council, the Wissenschaftsrat, had recommended the research institute on which it is based as one of the few institutes of the former East Germany's Academy of Science whose activities should be continued after reunification. Eigen supported the appointment of Schuster, an Austrian evolu- tionary biologist and one of his former students, as scientific director.

The institute was able to attract top-class scientists from west Germany and outside to take over key posts. But problems started after Schuster, frustrated at the bureaucratic difficulties he faced, resigned as scientific director in 1994 to go back to full-time research.

Schuster had tried to replace the leadership structure of the IMB, in which the administrative and scientific director share equal decision-making authority, with one that would have strengthened the influence of department heads. But his supporters say that his efforts were blocked by opposition from government officials.

After Schuster's resignation, complaints began to grow among the institute's 130 scientists about a repressive administrative regime and lack of support from the new scientific director. Scientists claim that their applications for research grants are needlessly delayed or held back by the administration. They also complain that the directors delayed releasing money received from research agencies, and about numerous trivial administrative requirements which distract them from their scientific work.

The difficulties are said to have been fanned by personal quarrels within the institute, and researchers' claims that a lack of open discussion has increased the atmosphere of mutual suspicion. For example, regular evaluation reports from the Wissenschaftlicher Beirat are passed to the Kuratorium but kept secret from the scientists involved.

A further source of conflict has been the issue of cooperation with industry, particularly EVOTEC, a Hamburg-based biotechnology company co-founded by Eigen, who, along with Rigler and Schuster, remain partners. Eigen claims that collaboration between EVOTEC and IMB has been deliberately hindered by the institute's directors - a charge the directors deny.

The non-German staff at the IMB, such as Schuster, appear to have suffered most from the problems. Last year the contracts of two of his four group leaders were not renewed - even though they were directing several large research projects with years to run.

The two scientists appealed to the Kuratorium and made their complaints public, both offences against official procedures, for which they were banned from IMB premises. As a result, they had to arrange to meet their PhD students privately.

Their departure - which Schuster says was "prompted by personal animosities not by scientific considerations" - caused a breakdown of relations throughout the insti-

\section{IMAGE UNAVAILABLE FOR COPYRIGHT REASONS}

Old meets new: traditional habits linger in Jena, an ancient town in former East Germany.

tute, and was one of the factors that led to Schuster's resignation as scientific director.

According to Diekmann, the IMB did not want to "reinforce the structure of Schuster's department" before a planned evaluation was carried out by the Wissenschaftlicher Beirat. Ironically, the loss of the two group leaders caused such disruption within the department that this evaluation has never been carried out. Schuster is now negotiating to relocate his entire group elsewhere in Germany.

Ministry officials have up to now sought to play down the problems at IMB. The official response to the Wissenschaftlicher Beirat's last report - which is said broadly to endorse Eigen's view and to call for farreaching changes in the institute's structure and for Diekmann's resignation - was that "all is well".

Rigler says this was the last straw for him, and prompted his resignation as head of the scientific council. He says the most important issue now facing the IMB is the authority of the scientific director, who, he believes, should be able to control the institute's budget without the direct approval of the administrative director.

But officials in the Thüringen research ministry see things differently. "Making administration subject to scientific demands is a mad idea," says Klaus Bartholmé, deputy director of the ministry and head of the Kuratorium. "It could bring the institute to ruin."

In the light of the recent resignations, however, and with key scientists leaving what they consider to be a sinking ship, Bartholmé admits that the IMB is in serious crisis. $\mathrm{He}$ now says that the Kuratorium may be prepared to make changes to the institute's statutes along the lines that were suggested by Rigler and Eigen.

But many researchers fear that the reputation of the institute has been so damaged that changes may come too late, and the institute may be hard-pressed to fill the newly vacant posts with scientists of the quality it used to be able to attract.

Quirin Schiermeier 